\title{
A Reconsideration of the Effectiveness of Using Geoboard in Teaching Euclidean Geometry
}

\author{
Mandlenkosi Richard Sibiya ${ }^{1^{*}}$ \\ ${ }^{1}$ School of Mathematics, Sciences and Technology Education, Faculty of Education, North West University, SOUTH AFRICA
}

Received 7 April 2020 - Accepted 31 May 2020

\begin{abstract}
The effect of using Geoboards in teaching Euclidean geometry in Grade 11 mathematics learners is described. A qualitative research design was adopted in the study. This design was preferred as it provides the conceptual understanding of the teaching methods of the teachers. The participants were taught Euclidean Geometry with the use of Geoboard and an assessment was done and marks were recorded. Thereafter, convenience sampling was used to select twenty ( $n=$ 20) participants from two secondary schools in the following order: eight $(n=8)$ of the top learners, four $(n=4)$ of the middle learners, and eight $(n=8)$ of the bottom learners were randomly selected from the Euclidean geometry test mark list to form four focus groups. Only five $(n=5)$ participants were assigned to each group. The study used the constructivism theory as the lens through which the data will be analyzed. The data were collected by means of focus groups and analyzed using thematic analysis. The findings of the study revealed that the Geoboard gives learners the freedom to learn on their own and in small groups while the teacher provides supervisory guideline using geometric theorem worksheets that support and guide learners. It was also noted that a Geoboard allows learners to work collaboratively with their peers while promoting learner-centered learning.
\end{abstract}

Keywords: geometric theorems, active learning, teaching method, Geoboards

\section{INTRODUCTION}

Vidermanova and Vallo (2014) have reported some of the cardinal points concerning the impact of the methods used for teaching Euclidean geometry to learners. The authors have indicated that the way learners are taught Euclidean geometry has a strong impact and influence on their ideas. The authors also further their discussion by indicating ways in which Euclidean geometry should be taught. Sibiya's (2018) study has made a crucial observation and contests that most teachers teach Euclidean geometry content as it is from the textbooks or without any new inputs or without further explanation.

Sibiya (2018) has supported his argument by pointing out that most teachers usually teach learners examples that are already given within the textbook, however, such practice has been noted to initiate fundamental problems to learners when they had to solve different problem or when facing exams containing much more advanced tasks as compared to the given examples in class (Mogari, Kriek, Stols, \& Iheanachor, 2009). As a matter of the fact, Hejný and Kurrina (2001) state that such a teaching approach (where a teacher is a transmitter of information) causes learners to remain passive listeners. As a result, learners tend to think that learning Euclidean geometry is difficult (Sibiya, 2019). Owing to that view, learners' performance in Euclidean geometry remains poor. Evidence of poor performance has been reported by several scholars such as Ali, Bhagawati, and Sarmah (2014) who mention that out of 120 learners in their study, $92(76.7 \%)$ learners failed a Euclidean geometry test and 28 (23.3\%) learners passed the Euclidean geometry test. This gives an impression that the poor performance of the learners might be strongly influenced by the teaching methods, in fact, Sibiya (2019) outlines that teaching geometric theorems is a problem for other teachers. In concurrence, Kuzniak and Rauscher (2011) reveal that the way teachers handle

(c) $\mathbf{2 0 2 0}$ by the authors; licensee Modestum. This article is an open access article distributed under the terms and conditions of the Creative Commons Attribution License (http://creativecommons.org/licenses/by/4.0/). 


\section{Contribution to the literature}

- Teaching Euclidean geometry using Geoboard promotes team-work amongst learners.

- Teaching Euclidean geometry using Geoboard promotes active learning in the classroom.

- Teaching Euclidean geometry using Geoboard develops learners' interest to learn Euclidean geometry.

- Teaching Euclidean geometry using Geoboard gives learners the freedom to learn on their own and in groups.

- Teaching Euclidean geometry using Geoboard allows learners to interact and work collaboratively with each other.

learners' answers differs with their conceptions of geometric work. In addition, the foundation of most teachers in Euclidean geometry is poor (Adolphus, 2011), as a result, their teaching methods will remain poor. Due to poor teaching methods, "many abstract concepts and formulae are taught without emphasizing important aspects such as understanding, reasoning and logic" (Karnasih \& Soeparno, 1999, p. 1). For that reason, active learning should be promoted as an alternative way to assist teachers to improve their teaching methods.

\section{BRIEF REVIEW ON ACTIVE LEARNING}

Researchers (Rahmiati, 2016; Scandrett, 2008) suggest the use of instructional materials as one of resolutions to promote active learning in the classroom in order to improve learners' performance in geometric concepts. Instructional materials are educational tools used to improve learners' learning skills and understanding, and also to increase learners' motivation levels of geometric understanding (Sani \& Salahudeen, 2016). Furthermore, these materials assist learners to be actively engaged in the learning process thereby promoting an active learning environment (Ali, Bhagawati, \& Sarmah, 2014). Jones (2003) also agrees that through the use of instructional materials such as GeoGebra and Geoboards, learners become extremely involved in activities where they could construct mathematical definitions and ascertain mathematical properties. In the active learning setting, teachers actively involve learners throughout the lesson (Cattaneo, 2017). Therefore, it can be argued that teachers' approach plays an important role in promoting an active leaning environment especially when teaching Euclidean geometry. Teachers need to be creative in designing geometric activities that would promote active learning (Michael, 2006). Active learning is an effective teaching strategy that aims to involve learners in the teaching and learning process (Johnson, Johnson, $\&$ Smith, 2006). In addition, active learning comprises an array of teaching and learning methods that can be very varied based on individual teacher's preferences (Cattaneo, 2017). McKeachie and Svinicki (2006) report three main characteristics of active learning, these are: the teacher is a facilitator not a lecturer; learners are expected to actively engaged in learning process and to build their own understanding of the geometric concepts; and lastly, active learning stimulates learners to develop higher-order thinking skills such as applying, analysing, evaluating and creating (Cattaneo, 2017).

Active learning promotes effective, collaborative group work among learners (Michael, 2006). Group work allows every learner to speak and share individual thoughts. Peer help and small group learning is highly recommended by several authors in the learning of Mathematics (Alegre-Ansuategui, Moliner, Lorenzo, \& Maroto, 2017). For instance, small-group discussions can be used in the geometry classroom, since these discussions assist learners to understand geometry concepts in addition to developing and improving their communication skills (Cattaneo, 2017). In the aforementioned study, learners were grouped in small groups so as to interact with Geoboards and Euclidean geometry worksheets to measure the angles and lengths of a given diagram. A Geoboard is a tool that is originally made of wood with nails driven halfway in and utilised with elastic bands to form different shapes with the nails. In an active learning classroom, teachers should not expect learners to listen and memorise concepts but should rather assist them in applying a concept to a reallife situation (Cattaneo, 2017). Moreover, an active learning setting means learners collaborate with everyone, engage with the physical tools such as Geoboard, and participate in the classroom. Presenting geometric concepts in an active learning setting, like teaching it using Geoboards, may give a solution to the problem of not engaging learners during the learning process. Thus, learners learn more when they are actively involved and given an opportunity to participate in the teaching and learning process, whether through mathematics applications, discussions or practice (Grunert, 1997).

A Geoboard is used to construct geometry theorem shapes and to explore their relationships (Furner \& Marinas, 2011; Scandrett, 2008). A Geoboard is a tool that is used to develop conceptual understanding of geometry (Sibiya, 2019). For instance, Geoboards assist learners in calculating the perimeter and area of any figure such as a circle or a square (Freire et al., 2018). Furthermore, a Geoboard helps learners increase their motivation level to learn geometric concepts (Rahmiati, 2016). Geoboards have a broad influence on the 
effectiveness of teaching and learning the geometric theorems and algebraic concepts (Abonyi \& Eze, 2006; Louis, 2001; Rahmiati, 2016; Scandrett, 2008). Despite the fact that the Geoboard seems to be useful, instructional material for teaching and learning of Euclidean geometry, does the Geoboard promote active learning of geometric theorems amid learners?

Based on the literature reviewed (Rahmiati, 2016; Scandrett, 2008; McKeachie \& Svinicki, 2006), learners can be actively engaged in constructing their own understanding of geometric concepts through active learning. Active learning can be exercised through the use of instructional materials such as Geoboards. However, most teachers teach geometric theorem sections without using instructional materials such as Geoboards (Rahmiati, 2016). The exclusion of instructional materials motivates this study to explore an alternative instructional material such as Geoboard that can be used to teach geometric theorems, while promoting active learning environment. To this end, research was launched to investigate the effectiveness of using Geoboards on promoting active learning, in particular, when learning Euclidean geometry. Based on the above, the following research question was formulated: How can Geoboards be used in teaching Euclidean geometry to promote active learning in the classroom?

\section{THEORETICAL FRAMEWORK}

The constructivist theory was used as a theoretical framework in this study. This theory, proposed by Piaget, mentions that learning happens by active construction of connotation not by inactive learning (Piaget, 1977). In other words, learners' existing knowledge should be considered as well as opportunities to put that knowledge into practice should also be provided during the teaching and learning process (Mvududu \& Thiel-Burgess, 2012). This can be done through active learning, where learners' prior knowledge is effectively linked with new knowledge. Owing to that, this theory focuses on the active role of learners in constructing their own knowledge by making sense of information and building understanding (Woolfolk, 2010). Constructivists believe that for learners to learn effectively, they need to construct their own meaning and understanding as well as make sense of their own experiences of the study phenomenon (Caffarella \& Merriam, 1999). In this regard, prior knowledge is the most important aspects of constructivist theory. Piaget concurs, in constructivism, learners take in knowledge, link it with prior similar knowledge and make it their own knowledge by constructing their own interpretations (Piaget, 1977).

Constructivists believe that learners learn by using what they know to build new understandings. So, when teaching any geometric concepts, a teacher should attempt to understand the "previous experiences and prior knowledge" of learners, and construct on this foundation (Bransford, Brown, \& Cocking, 1999). Constructivism suggests that the methods to promote active learning usually require learners to create connections amongst new information and their existing psychological models and prolonging their understanding (Cox-Petersen \& Olson, 2000; Steffe \& Gale, 1995). In other words, teachers can fashion learning activities that allow learners to defy misconceptions, assisting learners rebuild their psychological models based on specific understanding. One of the techniques used to promote active learning is demonstrations. For instance, in this study, learners were given Euclidean geometry worksheets and required to demonstrate geometry diagrams on Geoboards; learners were also asked to predict the outcome of a demonstrated diagram in terms of identifying equal angles before measuring those angles using a protractor. After demonstration, learners were asked to discuss the observed outcome and also state how they may have differed from their prediction. This method assisted learners to test their understanding of geometry theorems by predicting an outcome. Thus, learners were required to measure the angles using a given protractor to verify their prediction, hence, it assisted them to see possible misconceptions and stimulated them to reform their psychological model.

Constructivist theory was chosen as it provides learners with the opportunity to build their own knowledge by integrating their prior knowledge when interacting with Geoboards. The researcher used a Euclidean geometry task to find learners' prior knowledge, in addition, to understand the status quo. For instance, at the beginning of the lesson, learners were asked to define geometry terminology like center, radius, circle, diameter, tangent, arc, and chord. Furthermore, active participation was observed when learners were collaborating using Euclidean geometry worksheets and Geoboards as guided by the constructivist theory. The Geoboard was utilised to reestablish strategies for solving geometry problems. In other words, learners were expected to build their understanding and develop procedures for solving geometry problems using a Geoboard.

\section{RESEARCH METHODOLOGY}

\section{The Aim of the Investigation}

The aim of the study was to investigate the effectiveness of using Geoboards in teaching Euclidean geometry to promote an active learning environment. The focus section of Euclidean geometry in this study is Circle geometry. 


\section{Research Method}

A qualitative research design was adopted in the study. This design was preferred as it provides the conceptual understanding of the teaching methods of the teachers.

\section{Sampling}

In this study, convenience sampling was used to select twenty participants from two secondary schools in the King Cetshwayo District in the KwaZulu-Natal Province (in South Africa) in the following order: eight of the top learners, four of the middle learners, and eight of the bottom learners were randomly selected from the Euclidean geometry test mark list to form four focus groups. Five participants were assigned to each group; all of whom were taught geometry theorems using a Geoboard for two weeks. A focus group approach suited this study as it drew on participants' beliefs, attitudes, feelings, experiences, and reactions in a way in which would not be feasible using other methods, for example, one-to-one interviewing, observation or questionnaire surveys (Morgan \& Krueger, 1993).

\section{Research Instruments}

The study used interview schedules as a research instrument to collect data. The aim was to get lucidity on how learners perceived geometrical understanding of theorems when using a Geoboard. Each focus group took two hours during the interview process. The study lasted about two weeks and took place after school hours. The five participants in each group worked together and had discussions about the tasks in the form of a focus group interview. Interviews were voice recorded for capturing participants' responses.

\section{Data Analysis}

Thematic analysis was used to analyse the data collected. According to Braun and Clarke (2006, p. 97) thematic analysis is a method used for identifying, analysing and reporting themes within the data. The audio-recording of 20 participants was listened to a number of times to ensure accurate transcription and translation. As interviewees were interviewed in IsiZulu, the researcher translated all interviews into English.

\section{Trustworthiness Considerations}

The same population was used, and similar questions were asked from different participants to get reliable answers from participants.

\section{Ethical Consideration}

All participants involved in the study received informed consent and assent forms. Furthermore, the issues of confidentiality, anonymity, time, voluntary participation and benefits were clearly stated before taking part in the study.

\section{RESULTS}

A summary of the results for the four focus groups is presented under one theme that emerged: learners' views of the active learning of geometric theorems. This theme is discussed in the sections that follow. In the meantime, when respondents were asked how Geoboard assisted them in becoming actively involved in the learning process, the results were as follows:

\section{Learners' Views of the Active Learning of Geometric Theorems}

An active learning approach is another learning strategy which makes learning easier, which is not used in most of the schools in South Africa (from anecdotal evidence). This type of learning is easy because learners get to see how certain mathematics problems can be solved, from the initial stage to end. Most of the schools in South Africa use a traditional method, which is also known as a lecture method. In this method, a teacher becomes an active participant and learners become inactive participants (Baig, 2015). In other words, learners become information receiver while a teacher becomes information deliver.

Participant 1 stated that: "in an active learning classroom, the teacher walked in with a piece of chalk and a square board with a large circle drawn on it. Furthermore, that ignited an unfamiliar interest of what we were going to embark on that day. Before the teacher even told us we were going to study Euclidean geometry, the teacher presented the Geoboard to us and told us that we were going to use it for the section. This surely did catch our attention". The learners were grouped in smaller groups so that they could share their discoveries with each other from the entire practical session.

During the implementation of Geoboards, the guidelines were given to participants on how to use the Geoboard to create diagrams and measure the angles. Also, the researcher gave each group a worksheet with a list of theorems to work with. Instead of the learners being told what the theorem was, learners discovered it themselves. This is in line with the constructivist approach, which promotes active learning where learners learn through discovering concepts, principles, and facts on their own (Brown, 1989; Ackerman, 1996). In this regard, Participant 16 stated that: "this learning approach brought a great deal of satisfaction to $m e^{\prime \prime}$. Once the entire practice was over, the teacher went over each theorem and explained them on the chalkboard and discussed the proof with learners. Participants across different groups indicated that they became more interested to learn Euclidean geometry using Geoboards. Participant 20 said that: "As a learner, I was inspired and wanted to do more exercises, to improve my knowledge". 


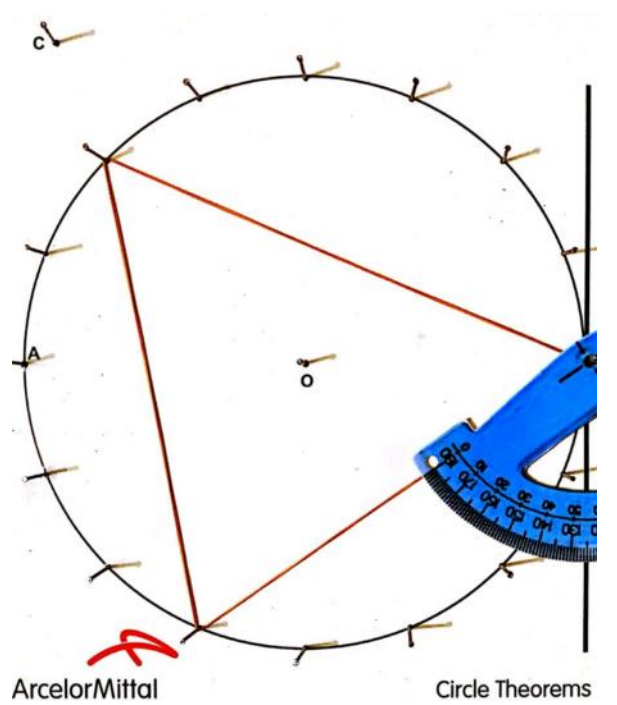

Figure 1. Screenshot of a Geoboard

Seeing the Geoboard for the first time made every learner want to learn. In addition, Participant 9 stated that: "for the first time since the beginning of the year, we were not following a tedious routine. We all know about the kinaesthetic learning style so the Geoboard helped those learners a great deal a lot". However, Participant 7 stated that: "to be honest, for some learner's books carry the nametag 'bore' so it was refreshing to see something different for a change".

The exercises brought a spirit of oneness among learners; learners worked as a team. The group activities enabled the learners to motivate each other, providing each other with clarification and developing the skill of teamwork. As the Geoboard was new to all learners, it was a challenge to use it in terms of creating the angles with the elastic band and measuring the angles. In this regard, the teacher was able to walk around to each group and assist learners with problems. More time was available for each group than for individual learners' work. Participants developed their confidence to learn Euclidean geometry. Participant 17 stated that: “We were working on how to construct and measure, not on how to prove already proven theorems. The environment was naturally stress-free and even hilarious at the same point" (See Figure 1).

In addition, Participant 6 said that: "Learning in a practical way is very pleasant because we get to practically construct the diagrams and accurately measure them. For example, Theorem 2 says that the angle at the center is twice the angle at the circumference of a circle. In the active learning environment, this theorem demonstrated to us and we practically proved Theorem 2 by constructing and measuring. Angles were measured using a protractor which makes it more fun and enjoyable to use because you can see it when you are doing it. It's unlike when it is being drawn on the chalkboard because you cannot do the measurements and it becomes very hard to prove the sums". Participant 6 's findings are shown in Figure 2.

Each participant within the group measured their own angles. By comparing the results with others in the group, they were able to conclude that $\hat{O} C=2 \times A \hat{B} C$. However, participants from different groups constructed a similar diagram for Theorem 2. Different participants got different angles. Figure 3 further corroborates the findings of the learners.

The research finding about the Euclidean geometry worksheet is that participants across all groups were able to measure the angles correctly and draw conclusions based on each diagram. Furthermore, participants were also required to construct and measure the alternate case of Theorem 2 (see Figure 4).

Participants across groups were able to construct and measure the angles of the alternate case of Theorem 2. It must be mentioned that the Geoboard is a small-sized

\section{THEOREM 2: ANGLE SUBTENDED BY AN ARC OR CHORD}

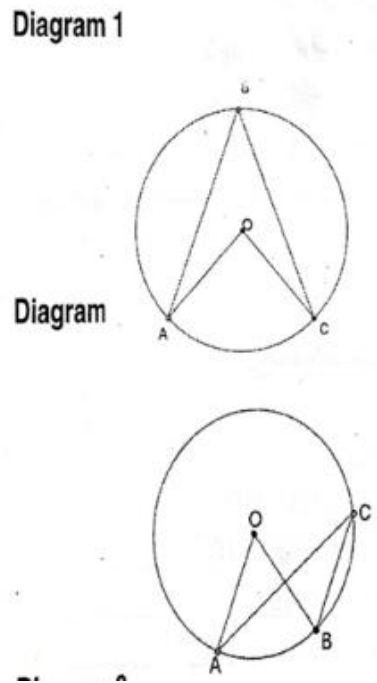

Figure 2. Theorem 2, angle subtended by an arc or chord
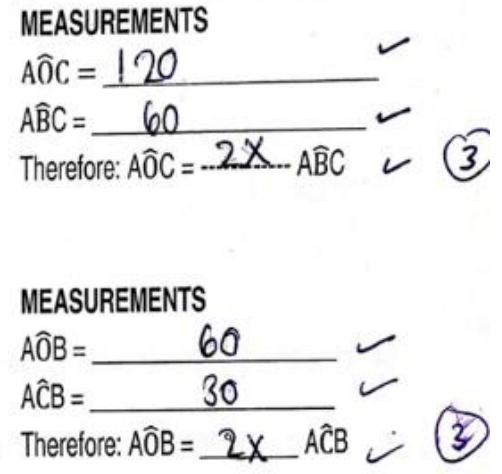


\section{THEOREM 2: ANGLE SUBTENDED BY AN ARC OR CHORD}

Diagram 1
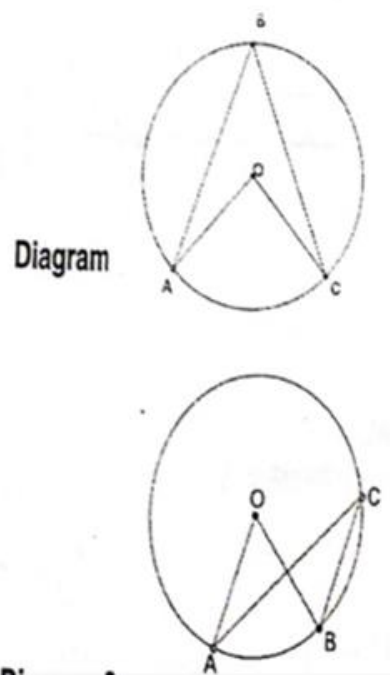

Figure 3 . Theorem 2, angle subtended by an arc or chord

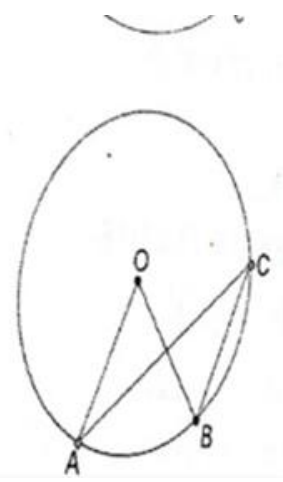

Figure 4. Alternate case of the Theorem 2

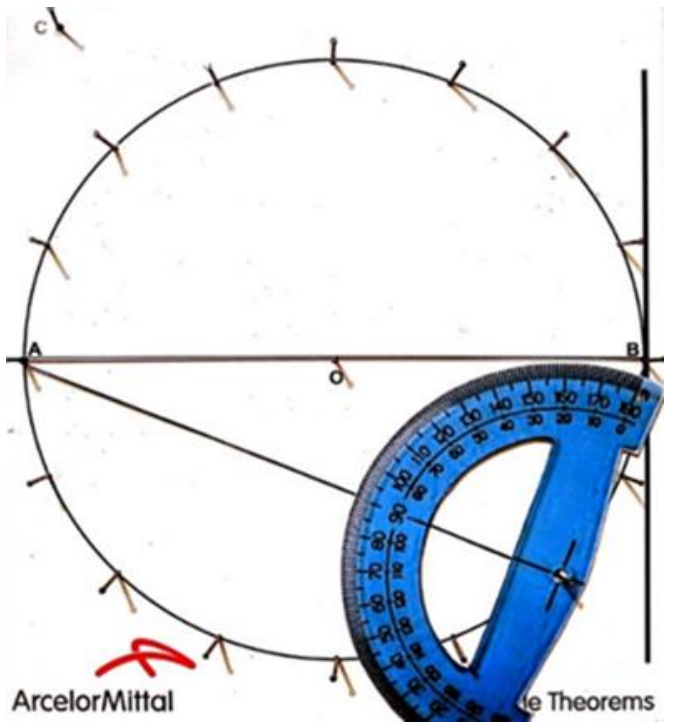

Figure 5. Screenshot of a Geoboard (participant 5)

board that can accommodate many theorem diagrams. In order to prove all the theorems practically, one needs

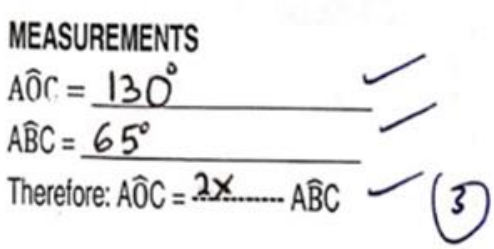

\section{MEASUREMENTS}
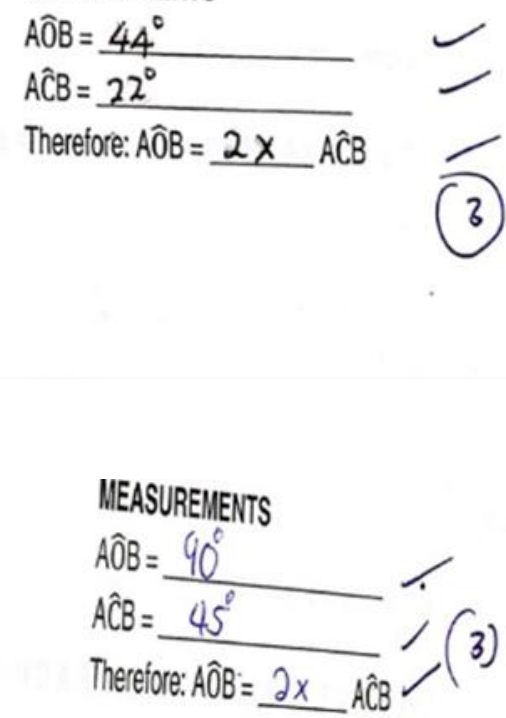

to use an elastic band to ensure the validity of the measurement, if one has constructed a diagram and measured it. A learner can also use an alternative way of constructing the very same diagram so that learners can be sure of the measurements. For instance, participants across groups also stated that no matter how the angle subtended by a diameter is placed, it will always be equal to $90^{\circ}$. Below are findings for participants 5 and 8 , from different groups (see Figures 5 and 6).

This simply means that the Geoboard has many advantages compared to using the chalkboard because learners can use different ways to prove the very same theorem, and when using the chalkboard, learners can only draw one diagram to prove that theorem without any hands-on experience. An active learning setting makes teaching and learning in class a pleasure because most of the time, learners use their hands to construct all diagrams. However, it is unlike the traditional teaching method where learners have to listen to the teacher and try to concentrate even though learners really do not understand. These findings are supported by Participant 


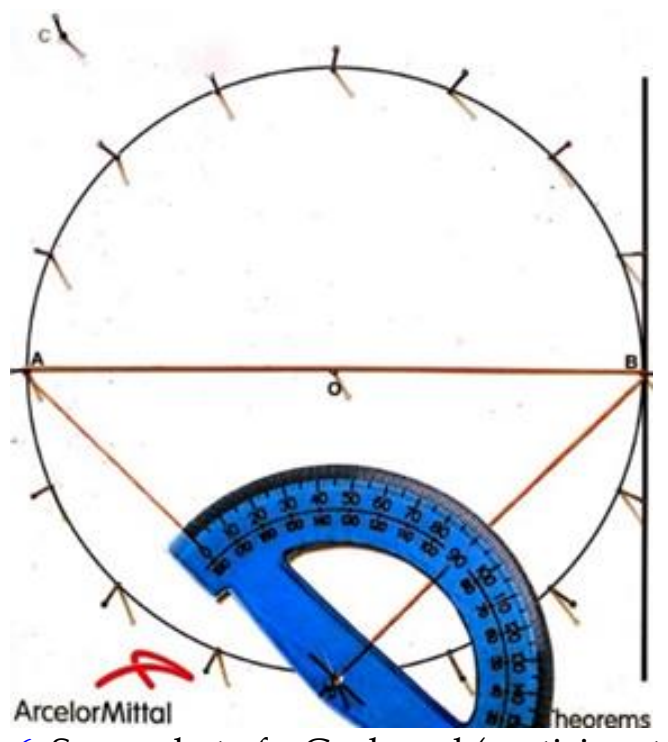

Figure 6. Screenshot of a Geoboard (participant 6)

13 who stated that: "As we know some of us lack listening skills, whereas it is very easy to just construct geometry diagrams using your hands. Thus, it is better to just do something yourself rather than having someone to do it for you".

In addition, learners viewed active learning approach in different ways.

Participant 16 stated that: "I personally prefer the active learning approach because I learn easily through demonstrations and cannot concentrate for a very long period and I think the Geoboard is way better than ordinary teaching because you get to use different teaching methods of proving and solving the geometry sums, and have to apply the basics learned".

A large number of learners stated that what is great with the Geoboard is that even when one is bored, he/she can create games like the board block challenge, which makes use of the circular Geoboard. Thus, these games combine reinforcement of properties of shape with higher-order thinking in terms of developing a winning strategy. Some other Geoboards help to explore the area. Happy Halving is an example of a task which develops learners' understanding of area by challenging them to halve the shapes on a square Geoboard. This could provoke some interesting discussion amongst the class as learners can be encouraged to explain, how they know that two halves are identical, possibly through some pencil and paper recording.

Participants became more excited and their attitude towards learning Euclidean geometry changed. These findings are supported by Participant 19 when she said that: "An active learning approach is very helpful especially in learning Euclidean geometry because you get to master the nine theorems without putting things in black and white. So I wish we could do it more often in schools and use them validly because I believe they can really change your mind towards Euclidean geometry since I was one of the pupils who were about to believe that I will never understand Euclidean geometry as much as I do now". In this regard, this kind of learning approach is important because some learners struggle to solve geometric problems without making practical observations.

\section{DISCUSSION OF RESULTS}

From learners' data, it was noted that in actual fact learners really want Geoboards in order to overcome their fears of Euclidean geometry and also to improve their active role in participating during the learning process. This study found that learners learn better when they are actively involved in the learning process and being part of knowledge construction. Similar results were obtained by (Grunert, 1997) who reports that learners learn more when they are vigorously engaged and given an opportunity to participate in the teaching and learning process, whether through mathematics applications, discussions or practice. Thus, Geoboards were used as a mathematics application to promotes active learning in this study.

The researcher also found that the use of Geoboards helps in promoting active learning and also in improving learners' motivation to participate in lessons. Similar results were obtained by Rahmiati (2016, p. 75) who reports that Geoboards can be offered in exciting ways to attract learners to play an active role in learning Euclidean geometry. This finding correlates very well with constructivist theory, which focuses on the active role of learners in constructing their own knowledge by making sense of information and building understanding (Woolfolk, 2010). Hence, learning occurs by active construction of meaning, not by passive learning (Piaget, 1977). In other words, in order to promote active learning, learners need to negotiate their understanding to accommodate the new learning experience (Hoover, 1996). Owing to that, learners used geometry worksheets to negotiate their existing knowledge with new knowledge when interacting with Geoboards. This is in line with constructivist beliefs, which suggest that methods to promote active learning usually require learners to create connections amongst new information and their existing psychological models and prolonging their understanding (CoxPetersen \& Olsen, 2000; Steffe \& Gale, 1995).

The researcher observed that the participants showed interest in the usage of Geoboards because; in their own words, "it enhances our learning skills". This finding is in line with Sani and Salahudeen (2016) who report that Geoboards stimulate learners' interest and make the learning of geometry more interesting and meaningful. This study also found that giving learners an opportunity to be actively involved in the lessons, will assist them to be able to discover their challenges themselves especially when solving geometry theorems. Another finding is that the Geoboard gives learners the freedom to learn on their own and in small groups while 
the teacher provides supervisory guidelines using geometric theorem worksheets that support and guide learners. Thus, it is also noted that in active learning environment, small groups are often used. Furthermore, several authors (Alegre-Ansuategui, Moliner, Lorenzo, \& Maroto, 2017) have recommended peer and small group learning in Mathematics. In support, Michael (2006) found that active learning promotes effective collaborative group work among learners. Hence, group activities enabled the learners to motivate each other, providing each other with clarification and developing the skill of teamwork. For instance, in this study, learners worked as a group on their Geoboard and each participant in a group was given an opportunity to construct geometry theorems on a Geoboard. After that, learners discussed their results with their group mates and elected one member to present group findings to the class, thus, promoting teamwork amid learners.

A further finding shows that Geoboards encourage learners to participate actively and be fully engaged in the learning process, while taking full responsibility to create their own understanding and meanings of geometric concepts. This finding complements those of Acharya (2017) who also reports that when using Geoboards in the teaching and learning process, learners become active, motivated, engaged, interested and collaborative in the Mathematics class. Also, it was noted that Geoboards made participants work collaboratively with their peers and the section (Euclidean geometry) became more practical and thus their understanding of the geometric theorems rapidly improved. This finding corresponds well with the constructivist approach, which promotes co-operative and active learning (Brown, 1994; Rogoff, 1998).

The researcher also found that, when using Geoboard, teachers should not expect learners to listen and memorise geometry concepts, but they should help them to apply a concept to a real-life situation. The researcher observed that lessons became more interesting and enjoyable when using active learning. Research evidence (from learners' data), learning Euclidean geometry using an active learning such as a Geoboard has assisted learners more in terms of developing a love for Euclidean geometry. After the participants were taught geometry theorems using the Geoboard, they were able to apply, analyse and evaluate theorems to solve any given geometry problems. Additionally, active learning is exercised. In support, Cattaneo (2017) found that active learning stimulates learners to develop higher-order thinking skills such as applying, analysing, evaluating and creating.

\section{LIMITATION OF THE STUDY}

The primary focus of this study was on the application of a Geoboard in Euclidean geometry for Grade 11 secondary school Mathematics learners in the
District of King Cetshwayo, in KwaZulu-Natal. It will be difficult to assume the results for the whole province. The study only focused on two schools. Fifty (50) Grade 11 Mathematics learners were selected as participants. The use of a small sample of 50 learners can bring into question the external validity of the findings.

\section{CONCLUSION}

After detailed research on the effect of the use of Geoboards in teaching Euclidean geometry in Grade 11 Mathematics learners to promote active learning, it was concluded that an active learning approach should be implemented in schools, because this type of learning helps learners be actively engaged in the learning process, in particular when interacting with Geoboards as a learning tool. This was validated (from learners' data) that some learners need to see how things are constructed and done. Hence, learners become actively involved in critical thinking when solving geometry problems. As a result, learners became in charge of their own learning. Thus, it can be concluded that learners really enjoyed learning Euclidean geometry using an active learning approach such as a Geoboard.

\section{ACKNOWLEDGEMENT}

The author is thankful to Mr Fhatuwani Sengani for his support and his words of encouragement, furthermore for content-editing the work. Also, the author is grateful to Dlangezwa High School and Ongoye High School for allowing the author to conduct the research.

\section{REFERENCES}

Abonyi, O., \& Eze, A. (2006). Effect of Geoboard on junior secondary school students' achievement in geometry. Ebonyi State University Journal of Education (EBJE), 4, 243-250.

Acharya, B. J. (2017). Factors affecting difficulties in learning mathematics by mathematics learners. International Journal of Elementary Education, 6(2), 815. https:/ / doi.org/10.11648/j.ijeedu.20170602.11

Adolphus, T. (2011). Problems of teaching and learning of geometry in secondary schools in Rivers State. International Journal of Emerging Sciences, 1(2), 143152.

Alegre-Ansuategui, F. J., Moliner, L., Lorenzo, G., \& Maroto, A. (2017). Peer Tutoring and Academic Achievement in Mathematics: A Meta-Analysis. Eurasia Journal of Mathematics, Science and Technology Education, 14(1), 337-354. https:/ / doi.org/10.12973/ejmste/79805

Ali, I., Bhagawati, S., \& Sarmah, J. (2014). Performance of Geometry among the Secondary School Students of Bhurbandha CD Block of Moigaon District. 
International Journal of Innovative Research and Development, 11(3), 73-77.

Baig, F. (2015). Application of Teaching Methods in Mathematics at Secondary Level in Pakistan. Pakistan journal of Social Sciences, 35(2), 935-946.

Bora, U. J., \& Ahmed, M. (2013). E-learning using cloud computing. International Journal on Science and Modern Engineering, 1(2), 1-5.

Bransford, J. D., Brown, A. L., \& Cocking, R. R. (1999). How people learn: Brain, mind, experience, and school. Washington, D.C.: National Academy Press.

Braun, V., \& Clarke, V. (2006). Using thematic analysis in psychology. Qualitative Research in Psychology, 3, 77 101. https:/ / doi.org/10.1191/1478088706qp063oa

Brown, A. L. (1994). The advancement of learning. Educational Researcher, 23(8), 4-12. https:/ / doi.org/ 10.3102/0013189X023008004

Caffarella, R. S., \& Merriam, S. B. (1999). Perspectives on adult learning: framing our research. Retrieved from http:/ / newprairiepress.org/cgi/viewcontent .cgi?article $=2825 \&$ context $=$ aerc

Cattaneo, K. H. (2017). Telling Active Learning Pedagogies Apart: from theory to practice. Journal of New Approaches in Educational Research, 6(2), 144152. https:/ / doi.org/10.7821/naer.2017.7.237

Cheek, D. W. (1992). Thinking Constructively About Science, Technology and Society Education. Albay, NY: State University of New York Press.

Cox-Petersen, A. M., \& Olson, J. K. (2000). Authentic science learning in the digital age. Learning $\mathcal{E}$ Leading with Technology, 27(6), 32-35.

Freire, A. F., Rodrigues, F. S., Aquino, M. R., Soares, M. V., Gois, D. D., \& Viana, J. D. (2018). The use of the Geoboard in teaching Geometry: calculating area and perimeter. Multidisciplinary Core scientific journal of knowledge, 3, 119-135.

Furner, J. M., \& Marinas, C. A. (2011). Geoboards to GeoGebra: Moving from the concrete 6 to the abstract in geometry. Retrieved from http:/ / archives.math.utk.edu/ICTCM/VOL23/S0 88/paper.pdf

Grunert, J. (1997). The course syllabus: A learning-centered approach. Bolton: Anker Publishing Co.

Hejný, M., \& Kuřina, F. (2001). Child, school and mathematics: constructivist approaches to teaching. Portal: Prague.

Hoover, W. A. (1996). The practice implications of constructivism. SEDL Letter, 9(3), 1-2.

Johnson, D. W., Johnson, R. T., \& Smith, K. A. (2006). Active Learning: Cooperation in the College Classroom. Edina, MN: Interaction Book Company.

Jones, K. (2003). Issues in the teaching and learning of geometry. In Aspects of teaching secondary mathematics (pp. 137-155). Routledge.
Karnasih, I., \& Soeparno. (1999). Teaching mathematics has to focus on logic. Indonesia: Kompas.

Khobo, R. J. (2015). The effect of using computers for the teaching and learning of mathematics to grade 10 learners at secondary school. Pretoria: University of South Africa. (Dissertation - M. Ed).

Kuzniak, A., \& Rauscher, J. C. (2011). How do teachers ${ }^{e e}$ approaches to geometric work relate to geometry

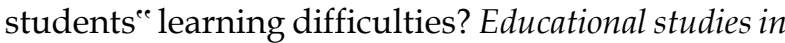
Mathematics, 77(1), 129-147. https://doi.org/ 10.1007/s10649-011-9304-7

Louis, E. U. (2001). Effect of using Geoboard in proofs of geometric theorems on students' achievements (Ph.D. Thesis). Nigeria: University of Nigeria.

Manoah, S. A., Indoshi, F. C., \& Othuon, L. O. (2011). Influence of attitude and performance of students in mathematics curriculum. Educational Research, 2(3), 965-981.

Mata, M., Monterio, V., \& Peixoto, F. (2012). Attitudes towards Mathematics: Effects of individual, motivational and social support factors. Journal of Child Development Research, 10, 1-10. https:/ / doi.org/10.1155/2012/876028

McKeachie, W., \& Svinicki, M. (2006). Teaching tips: strategies, research, and theory for College and University teachers. Belmont: CA: Wadsworth.

Michael, J. (2006). Where's the evidence that active learning works? Advance in Physiology Education, 30, 159-167. https://doi.org/10.1152/advan.00053. 2006

Mogari, D., Kriek, J., Stols, G., \& Iheanachor, O. (2009). Lesotho's Learners' Achievement in Mathematics and their Teachers Background and Professional Development. Pythagoras, 70, 3-15. https:// doi.org/10.4102/pythagoras.v0i70.33

Morgan, D. L., \& Krueger, R. A. (1993). Successful focus groups: Advancing the state of the art. In $\mathrm{D}$. Morgan (Ed.), When to use focus groups and why. Newbury Park: Sage. https://doi.org/10.4135/ 9781483349008

Mvududu, N. H., \& Thiel-Burgess, J. (2012). Constructivism in practice: The case for English language learners. International Journal of Education, 4(3), 108-118. https://doi.org/10.5296/ije.v4i3. 2223

Piaget, J. (1977). The development of thought: Equilibration of cognitive structures. New York: The Viking Press.

Rahmiati, M. (2016). The attempt to improve mathematics learning motivation using the geoboard (Spiked Board) Among Grade II Elementary School Students. Global Journal of Business and Social Science Review, 4(3), 74-78. 
Ramanujam, R., \& Subramaniam, K. (2012). Mathematics Education in India: Status and Outlook. Mumbai: Homi Bhabha Centre for Science Education.

Rogoff, B. (1998). Cognition as a collaborative process. In W. Damon, D. Kuhn, \& R. S. Seigler (Eds.), Handbook of child psychology (5 ed., Vol. 2). New York: Wiley.

Sani, S., \& Salahudeen, B. (2016). Effects of Geoboard and geographical globe on senior secondary school students' performance in mathematics in Kaduna state. Journal of Science, Technology E Education, 4(1), 140-148.

Scandrett, H. (2008). Using Geoboards in primary mathematics: Going...going...gone? Australian Primary Mathematics Classroom, 13(2), 29-32.

Sibiya, M. R. (2018). Exploring the use of a Geoboard in the teaching and learning of Euclidean geometry among grade 11 mathematics learners in King Cetshwayo District (M. Ed. Dissertation). Durban: University of KwaZulu-Natal.

Sibiya, M. R. (2019). The effect of Geoboard use on learners' motivation for learning of Geometry theorems. International Journal of Sciences and Research, 75(6), 71-85. https://doi.org/10.21506/ j.ponte.2019.6.14

Steffe, L. P., \& Gale, J. (1995). Constructivism in education. Hillsdale, NJ: Lawrence Erlbaum Associate, Inc.

Vidermanova, K., \& Vallo, D. (2014). Practical Geometry Tasks as a Method for Teaching Active Learning in Geometry. Procedia - Social and Behavioral Sciences, 191(2015), 1796-1800. https://doi.org/10.1016/ j.sbspro.2015.04.421

Woolfolk, A. (2010). Educational psychology (11 Ed.). Upper Saddle River: Pearson Education, lnc.

\section{http://www.ejmste.com}

